\title{
Assessment of a Dietary Consultation Model for Effective Diabetes Care in Saudi Population using Partial Least Squares Estimation
}

\author{
Waqas Sami \\ Public Health \& Community Medicine, \\ College of Medicine, Majmaah University, 11952, Kingdom of Saudi Arabia \\ w.mahmood@mu.edu.sa \\ Tahir Ansari \\ Department of Clinical Sciences, \\ College of Medicine, Majmaah University, 11952, Kingdom of Saudi Arabia \\ t.ansari@mu.edu.sa \\ Nadeem Shafique Butt \\ Department of Family \& Community Medicine, \\ College of Medicine in Rabigh, King Abdulaziz University, Jeddah, Kingdom of Saudi Arabia \\ nadeemshafique@ hotmail.com \\ Mohd Rashid Bin Ab Hamid \\ Faculty of Industrial Management, \\ Universiti Malaysia Pahang, Lebuhraya Tun Razak, 26300 Gambang, Kuantan, Pahang, Malaysia \\ rashid@ump.edu.my
}

\begin{abstract}
The relationship between dietary habits and diabetes has not been studied efficiently in Saudi Arabia and the available diabetes risk models does not focus much on diet, nor do they capture the overall dietary behaviors. The purpose of this research was to test empirically the hypothesised dietary consultation model that has been proposed for more effective diabetes care. This exploratory study was conducted on type 2 diabetic Saudi patients visiting the Primary Health Care Centres in Almajmaah city. The data comprising 350 patients were collected from $5^{\text {th }}$ February $-24^{\text {th }}$ April, 2017 through systematic sampling technique using direct investigation method. Data was collected through four questionnaires. Composite scores were extracted for all variables under study and analysed by Partial Least Squares-Structural Equation Modelling approach using SmartPLS 3.2.6 software. Evaluation of formative outer and inner model relationships validated the hypothesised dietary consultation model. Power of study, coefficient of determination, effect size, total effects, and model fit index further validated the findings. The validated dietary consultation model facilitates a new healthcare paradigm which can give a better understanding of diabetes management at stakeholder and individual level. Healthcare givers should pay special emphasis on diabetics' diabetes mellitus knowledge, dietary knowledge, and dietary attitude, as these factors influence each other, dietary practices and $\mathrm{HbA} 1 \mathrm{c}$. Healthcare givers can use this model alone or by integrating it with available diabetes risk models to carry out the dietary assessment of type 2 diabetics.
\end{abstract}

Keywords: Dietary Assessment, Type 2 Diabetes Mellitus, Saudi Arabia, Dietary Consultation Model, Structural Equation Modelling.

\section{Introduction}

According to 2016 estimates, the population of Kingdom of Saudi Arabia (KSA) is over 18 million and is rapidly growing. The prevalence of Type 2 Diabetes Mellitus (T2DM) in KSA is increasing at an alarming level, every other adult, aged above 30, is prone to diabetes (Wild et al., 2004). Several studies consider the Saudi prevalence of T2DM as an 
epidemic, average ranging from 16\%-35\%. It has many serious microvascular and macrovascular complications. Factors like poor dietary habits, sedentary lifestyle, increasing age, obesity and a person's genetic profile, all are well known to be associated with diabetes and its complications (Akram et al., 2011; Caballero, 2005). A report published in Arab news by Irfan (2012) stated that the cost of treating diabetes in KSA had been reported as high as about 30 billion Saudi Riyals (SAR). The annual cost of treating an uncomplicated case of diabetes comes to around SAR 5,000, while it soars up to 38 times (SAR 180,000) with the addition of any one diabetes complication.

There is lack of literature regarding the dietary assessment of type 2 diabetics in KSA. According to World Health Organization (WHO, 2005), the prevalence data on physical inactivity and dietary patterns in the Saudi population are scarce, with no reliable published study. The relation between dietary habits and diabetes has not been studied efficiently in KSA as literature related to diet-diabetes is very limited (Mohamed et al., 2013; Ng et al., 2011; Amini, 2012). The current gap in dietary evidence in KSA urges for further studies to be conducted to understand diet-diabetes relation in more detail (AlKhudairy et al., 2013). An intensive literature review was conducted to initiate this research. Five domains namely diabetes mellitus knowledge (DMK), dietary knowledge (DK), dietary attitude (DA), dietary practices (DP) and haemoglobin A1c (HbA1c) were identified as influential factors in the dietary assessment of type 2 diabetics (Sami, Ansari, Butt \& Hamid, 2017, 2016).

\subsection{Development of Hypothesis}

Studies have documented knowledge as a requirement for people and societies for inhibition, handling, and control of chronic diseases like diabetes (Saleh et al., 2012; Raj \& Angadi, 2010). Mufunda et al. (2012), recommended addressing the knowledge gaps between DMK and diet in diabetes education programmes with sheer emphasis, as not addressing these gaps can influence the development of diabetes complications. Ntaate (2015), also reported a gap between disease and DK. It has been stated in another study that dietary pattern and food selection is influenced by patient's knowledge related to recommended diet (Tesfaye et al., 1996). Literature addressing the relationship between DMK and DP is non-existent, our study is the first to analyze this relationship. Thus we hypothesised that:

H1: Diabetes mellitus knowledge has an influence on dietary knowledge.

$\mathrm{H} 2$ : Diabetes mellitus knowledge has an influence on dietary practices.

DK and DA have been identified as potential mediators in any diet-related behaviors, these factors should be addressed in any diabetes diet-focused intervention (Contento, 2007). DK has been specified to be a significant factor that influences dietary behaviors (Backman et al., 2002). More studies have documented nutritional knowledge as an important factor to achieve positive attitude towards healthy eating (Mirmiran, Azadbakht \& Azizi, 2007; Brown \& Ogden, 2004). Findings of another study reported 
DK and DA as essential factors in making healthy food choices (Coon, 2001). DP fall in the domain of self-management of disease. Diabetics who have a deficiency in knowledge related to the diet cannot develop a dynamic and reliable role in disease selfmanagement (Saleh, Ara \& Afnan, 2016). Various studies have documented knowledge as an essential resource that can guide diabetics about their practices (Kigaru et al., 2015; Sindhu, 2014). Nutritional education although is necessary to perceive dietary practices, however, still a big gap exists between these two factors (Girosis et al., 2001). Thus we hypothesised that:

H3: Dietary knowledge has an influence on dietary attitude.

H4: Dietary knowledge has an influence on dietary practices.

DA can help in measuring the effects of dietary outcomes in non-communicable diseases (Worsley, 2002). DA can be influenced by intrinsic and extrinsic factors like food restraint, healthy choices, and hunger, etc. Positive DA with good nutritional knowledge is likely to display long-term beneficial effect on DP. Aesthetic or scientific values of food can be related to observing dietary patterns of individuals, these values can significantly influence one's dietary choices (Yaktine \& Stallings, 2007). Poor control of diabetes among type 2 diabetics is related to inappropriate DA and unhealthy DP (Amorim et al., 2014). Attention should be given to diabetics' nutrition status as this has an overall impact on the attitude that can be translated into healthy practices (Waithaka, 2011). Thus we hypothesised that:

H5: Dietary attitude has an influence on dietary practices.

To improve the risk profile of diabetic patients and delay the onset of diabetes complications, a primary and essential measure is to have appropriate DP. Controlling diet can reduce $\mathrm{HbA1c}$ by $1-2 \%$. However, this improvement in $\mathrm{HbA1c}$ is related to limiting caloric intake and reducing weight (Monnier et al., 2004; Pastors et al., 2002). Importance of diet in diabetes management is well accredited, however, practically, deficiency in dietary compliance in T2DM is a main restrictive factor in achieving good glycemic control (Pi-Sunyer et al., 1999). A study conducted on DP of type 2 diabetics in KSA reported overall inadequate DP (Mohamed et al., 2013). Studies conducted internationally and in Gulf Cooperation Council (GCC) countries reported that a significant association exists between DP and HbA1c (Al-Kaabi et al., 2008; Lanting et al., 2008; Nasser, 2007; Hearnshaw \& Lindenmeyer, 2006). Thus we hypothesised that:

H6: Dietary practices have a direct influence on HbA1c.

The prime purpose of this research is to empirically validate the dietary consultation model. This was carried out by 1) describing the effect of DP on HbA1c which is considered as a contributing factor for developing both microvascular and macrovascular diabetes complications. The hypothesized factors that can influence DP are "DMK, DK, and DA." In addition, the interrelationship of DMK, DK, and DA was also studied as shown in Figure 1 and Figure 2. 


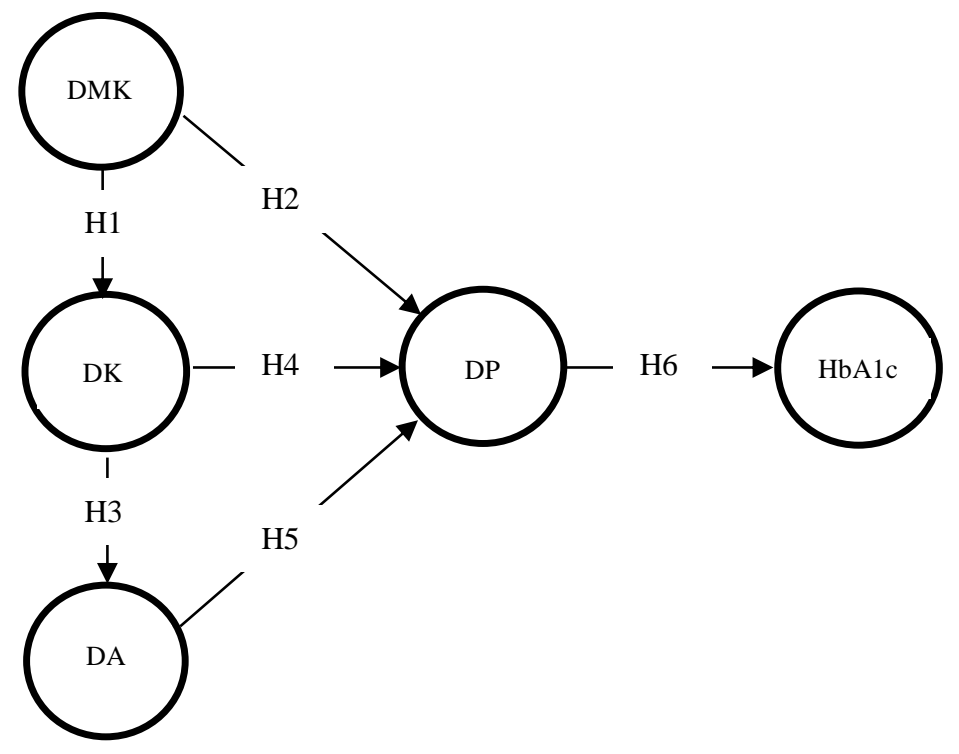

Figure 1: Hypothesised Dietary Consultation Model

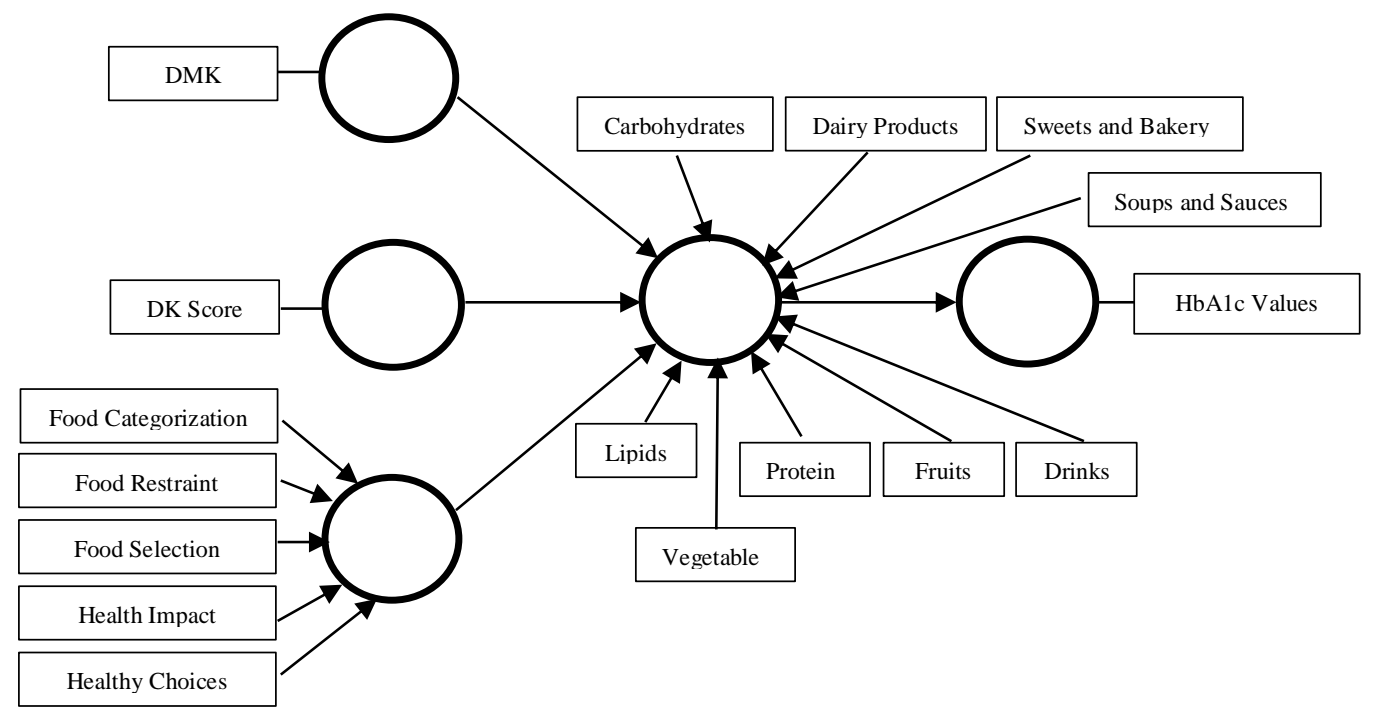

Figure 2: Full Research Model with Indicators

\section{Material and Methods}

This exploratory study was conducted on type 2 diabetic Saudi patients visiting the Primary Health Care Centres (PHC's) in Almajmaah city. The data was collected from $5^{\text {th }}$ February $-24^{\text {th }}$ April, 2017 through systematic random sampling technique using direct investigation method. G*Power 3.1.9.2 for windows was used to calculate the sample size. A maximum number of arrows pointing to the formative constructs were 9 , to 
achieve a statistical power of $80 \%$ at $5 \%$ level of significance with a minimum $\mathrm{R}^{2}$ of 0.10, the required sample size was 181 subjects (Cohen, 1992). However, keeping in view the precision, generalizability, missing values, patients withdrawing from the study and presence of outliers, the sample size was increased to 350. The latest value of HbA1c was taken from patient's record present in the PHC's. Inclusion criteria were 1) known type 2 diabetics since five years, 2) aged between 35-55 years, 3) both gender, i.e., males and females and 4) having no other co-morbidities. Exclusion criteria were, 1) patients with type 1 diabetes and other chronic diseases, 2) patients with age less than 35 years and more than 55 years and 3) other co-morbidities. Written informed consent was taken from the patients prior to data collection and anonymity was maintained. This research was approved by the ethical review committee of Majmaah University, KSA vides reference no: MURECApril.02/COM-2016.

\subsection{Instruments for Data Collection}

There is a scarcity of literature in KSA about the availability of standardized questionnaires for carrying out a dietary assessment of type 2 diabetics. As dietary habits vary from country to country, therefore, we attempted to develop questionnaires that can serve as a baseline for carrying out the dietary assessment. Through rigorous literature review, four questionnaires assessing/evaluating DMK, DK, DA, and DP were developed/modified and subsequently tested for psychometric properties (Sami, Ansari, Butt \& Hamid, 2017). Composite scores obtained from each questionnaire were used in Structural Equation Modeling (SEM) analysis (Henseler, 2017).

\subsection{Structural Equation Modelling}

SEM is a powerful second-generation multivariate tool for studying interrelationships simultaneously among multiple observed and latent variables (Hair, Ringle \& Sarstedt, 2011). Partial Least Square-Structural Equation Modeling (PLS-SEM) is an Ordinary Least Square (OLS) regression-based estimation technique. In this research, a formative model was used. The selection of formative model was based on 1) its definition, 2) discussion with experts, 3) keeping in view the model selection criteria's and 4) nature of study variables. In the formative model, indicators are not interchangeable, if an indicator is deleted, the underlying construct can be meaningless as a part of it is omitted (Hair et al., 2006). However, the indicators may have no, low, medium or high correlations among them. After selecting the type of model, next step was to carry out the evaluation of formative measurement model (outer model) and assessment of structural model (inner model) that is explained in Table 1.

\section{Table 1: Assessment criteria for outer formative and inner model}




\section{Outer Model}

Convergent Validity

Collinearity

Significance \& relevance of formative indicators

\section{Description}

The magnitude of 0.70 and above is recommended for the construct to meet convergent validity (Hair et al., 2016).

A Variance Inflation Factor (VIF) value $\geq 5$ indicates a potential problem of collinearity between indicators and constructs (Hair et al., 2016).

Running bootstrapping procedure with 5000 replicates selected with-replacement. Indicator weight's significance was evaluated by t-values and p-values (Hair et al., 2016; Jahner, Leimeister, Kenebel \& Krcmar, 2008).

\begin{tabular}{|c|c|}
\hline Inner Model & Description \\
\hline Collinearity & $\begin{array}{l}\text { A VIF value } \geq 5 \text { indicates a potential problem of } \\
\text { collinearity between constructs (Hair et al., 2016). }\end{array}$ \\
\hline $\begin{array}{l}\text { Assessing the significance } \\
\text { and relevance of structural } \\
\text { model relationships }\end{array}$ & $\begin{array}{l}\text { Running bootstrapping procedure with } 5000 \text { replicates } \\
\text { selected with-replacement. Path coefficients significance } \\
\text { was evaluated by t-values and p-values (Chin, 1998). }\end{array}$ \\
\hline $\begin{array}{c}\text { Coefficient of } \\
\text { Determination }\left(\mathrm{R}^{2}\right)\end{array}$ & $\begin{array}{l}<0.19: \text { no effect; 0.20-0.33: weak; 0.34-0.67: moderate } \\
\text { and >0.67: substantial (Chin, 1998). }\end{array}$ \\
\hline Effect Size $\left(\mathrm{f}^{2}\right)$ & $\begin{array}{l}0.02 \leq \mathrm{f}^{2}<0.15: \text { weak effect; } 0.15 \leq \mathrm{f}^{2}<0.35 \text { : moderate } \\
\text { effect and } \mathrm{f}^{2} \geq 0.35 \text { : strong effect (Hair et al., 2016). }\end{array}$ \\
\hline Model Fit & $\begin{array}{l}\text { Standardized Root Mean Square Residual (SRMR) with a } \\
\text { cutoff criterion < } 0.08 \text { was used as a model fit measure } \\
\text { (Hair et al., 2016; Hu \& Bentler, 1999). }\end{array}$ \\
\hline
\end{tabular}

\subsection{Data Analysis}

Preceding to data analysis, the data were screened for typographically wrong entries and missing values by using IBM SPSS 23.0 (IBM Corp., Armonk, N.Y., USA). Median $\left(25^{\text {th }}\right.$ quartile $-75^{\text {th }}$ quartile) is reported for non-normally distributed quantitative variables. Frequencies and percentages are reported for qualitative variables. Mahalanobis distance, a multivariate technique was used to identify the outliers before running the SEM analysis. Any value < 0.001 should be considered as an outlier (Peat \& Barton, 2008). The data was then screened for normality, collinearity and common method bias (Pallant, 2011; Tabachnick \& Fidell, 2007). PLS-SEM was used to test the hypothesized model using exploratory modelling analysis via SmartPLS 3.2.6. A p-value of $<0.05$ was considered as statistically significant.

\section{Results}

The median age of the patients was 45 (40-51) years. Majority of the patients were males as compared to females (57.7\% vs $42.3 \%)$. The family history of diabetes was positive in $40 \%$ of the patients. Almost $50 \%$ of the patients were overweight, followed by obese $32.9 \%$, normal weight were $16 \%$, and only $3.4 \%$ patients were underweight. Based on 
HbAlc, majority of the patients $50 \%$ had poorly controlled diabetes (> $58 \mathrm{mmol} / \mathrm{mol}$ ), one-quarter of patients had partially controlled diabetes $(47-58 \mathrm{mmol} / \mathrm{mol})$, and only $18.6 \%$ had good diabetes control (37-46 mmol/mol).

Mahalanobis distance showed the presence of outliers, 14 cases had p-value less than 0.001. The final dataset for SEM analysis contained 336 cases. Normality of data was checked through an online freely available software to assess multivariate skewness and kurtosis (Ramayah et al., 2017). Results of skewness and kurtosis obtained from https://webpower.psychstat.org/models/kurtosis/results.php?url=955cb020081037157f40 $\underline{87 \mathrm{e} 130 \mathrm{ca} 059 \mathrm{~b}}$ showed that data was multivariate non-normal. Mardia's multivariate skewness $(\beta=42.88, \mathrm{p}<0.001)$ and Mardia's multivariate kurtosis $(\beta=350.02, \mathrm{p}<$ $0.001)$. Multicollinearity was evaluated through bivariate correlations and regression analysis. Results showed that all bivariate correlations were $<0.90$ cutoffs, whereas, all tolerance values were above 0.20 and VIF for each independent variable was < 5 . Hence, no multicollinearity problem existed among the variables. Common method bias was evaluated through Harman's one-factor test. Ideally, no single factor should explain more than $50 \%$ of the variation. Exploratory Factor Analysis (EFA) showed that maximum variance explained by one factor was $34.23 \%$ that had Eigenvalue of 5.819. Hence it was confirmed that common method bias was not an issue in this study.

\subsection{Assessment and Evaluation of Outer Model Relationships}

\subsubsection{Assessing Convergent Validity (Redundancy Analysis)}

To assess Convergent Validity (CV), a reflective global scale item (measuring the essence of rest of the formatively measured items) was included in each questionnaire. In addition, DP questionnaire had 9 food groups, a reflective global scale item was included for each subgroup as all foods groups were independent of each other. Redundancy analysis results presented in Table 2 showed that all questionnaires displayed evidence of $\mathrm{CV}$ as all path coefficients were $\geq 0.70$.

\subsubsection{Assessing Collinearity among Indicators and Constructs}

VIF values for outer model presented in Table 2 are uniformly less than the cutoff value 5. Hence, we conclude that multicollinearity is not an issue for estimation of PLS path model.

\subsubsection{Significance and Relevance of Formative Measurement Model Outer Weights}

Significance and relevance of outer weights were assessed by means of bootstrapping procedure. Results presented in Table 2 showed that outer weights of all formative indicators are significant. Moreover, outer weights of all indicators are more than 0.10. Therefore, we can conclude that each indicator of the related formative construct is considered important in explaining the construct's domain.

\section{Table 2: Formative outer model evaluation}




\begin{tabular}{ccccccc}
\hline Construct & CV & VIF & Indicators & $\begin{array}{c}\text { Outer } \\
\text { Weights }\end{array}$ & t-value & p-value \\
\hline DMK & 0.839 & 1.000 & DMK Score & Single item quantitative & $<0.001^{*}$ \\
DK & 0.935 & 1.000 & DK Score & Single item quantitative & $<0.001^{*}$ \\
& & 1.659 & Food Selection & 0.228 & 3.411 & $<0.001^{*}$ \\
DA & 0.853 & 1.258 & Health Impact & 0.368 & 6.453 & $<0.001^{*}$ \\
& & 1.274 & Healthy Choices & 0.139 & 2.552 & $0.012^{\mathrm{f}}$ \\
& & 2.007 & Food Categorization & 0.500 & 6.523 & $<0.001^{*}$ \\
& 0.932 & 1.543 & Proteins & 0.195 & 3.723 & $<0.001^{*}$ \\
& 0.878 & 2.162 & Carbohydrates & 0.445 & 7.575 & $<0.001^{*}$ \\
& 0.887 & 1.432 & Lipids and Fats & 0.305 & 5.762 & $<0.001^{*}$ \\
DP & 0.974 & 1.081 & Dairy Products & 0.157 & 3.768 & $<0.001^{*}$ \\
& 0.916 & 2.378 & Sweets and Bakery & 0.207 & 4.174 & $<0.001^{*}$ \\
& 0.806 & 1.254 & Drinks & 0.123 & 2.755 & $0.002^{\mathrm{f}}$ \\
& 0.790 & 1.049 & Fruits & 0.125 & 3.086 & $0.008^{\mathrm{f}}$ \\
& 0.853 & 1.062 & Vegetables & 0.120 & 3.404 & $0.002^{\mathrm{f}}$ \\
& 0.822 & 1.025 & Soup and Sauces & 0.113 & 2.649 & $0.005^{\mathrm{f}}$ \\
HbA1c & --- & 1.000 & HbAlc & Single item quantitative & $<0.001^{*}$ \\
\hline
\end{tabular}

*significant at $1 \%$ level of significance

${ }^{\mathrm{I}}$ significant at $5 \%$ level of significance

\subsection{Assessment and Evaluation of Inner Model Relationships}

Before formal assessment of structural model also known as an inner model, power (1- $\beta$ ) was calculated to validate the empirical findings of the study by using G*Power 3.1.9.2. Results showed that this study achieved a power of $100 \%$ with a significance level of 0.05 (two-tailed), a sample size of 336 and effect size of 0.30 (medium effect). Power achieved in this study exceeds the cutoff value 0.80 (Cohen, 1992).

\subsubsection{Examining Structural Model (Inner Model) for Collinearity Issues}

To assess a structural model for collinearity issues, same diagnostic measure, i.e., VIF was used. VIF values were examined for all set of predictor variables. Results presented in Table 4 showed that collinearity is not a problem among the predictor variables as all values were less than the cutoff value 5 .

\subsubsection{Assessment of Significance and Relevance of Inner Model Relationships}

The same bootstrapping procedure was used to assess the significance and relevance of inner model relationships. The significance of paths was determined by examining path loadings, $\mathrm{t}$-values, and $\mathrm{p}$-values. Results showed that all path coefficients were significant at $\mathrm{p}<0.001$. Moreover, the magnitude of all path coefficients was > 0.20 (Chin, 1998). Hence, significance and magnitude of inner model path coefficients confirm that the research model has adequately established nomological validity as shown in Table 3.

\section{Table 3: Significance of hypothesized relationships}




\begin{tabular}{ccccc}
\hline Path & Beta & t-value & p-value & Result \\
\hline $\mathbf{D M K} \rightarrow$ DK & 0.660 & 20.853 & $<0.001^{*}$ & Supported \\
$\mathbf{D M K} \rightarrow$ DP & 0.263 & 5.304 & $<0.001^{*}$ & Supported \\
$\mathbf{D K} \rightarrow \mathbf{D A}$ & 0.686 & 21.236 & $<0.001^{*}$ & Supported \\
$\mathbf{D K} \rightarrow$ DP & 0.365 & 5.606 & $<0.001^{*}$ & Supported \\
$\mathbf{D A} \rightarrow \mathbf{D P}$ & 0.324 & 4.950 & $<0.001^{*}$ & Supported \\
$\mathbf{D P} \rightarrow \mathbf{H b A 1 c}$ & 0.739 & 28.325 & $<0.001^{*}$ & Supported \\
\hline
\end{tabular}

* significant at $1 \%$ level of significance (two-tailed)

\subsubsection{Coefficient of Determination $\left(\mathbf{R}^{2}\right)$}

In this research, there were four endogenous (DK, DA, DP, and HbA1c) and one exogenous variable (DMK). $\mathrm{R}^{2}$ values of $\mathrm{DK}, \mathrm{DA}$, and HbA1c were moderate, whereas, DP had a substantial $\mathrm{R}^{2}$ value. DMK significantly explained $43.5 \%$ variation in $\mathrm{DK}$ construct. Whereas, DK significantly explained $47.1 \%$ variation in DA construct. Moreover, DMK, DK, and DA significantly and substantially explained $68.1 \%$ variation in DP construct. Nevertheless, DP significantly predicts HbAlc with a healthy $\mathrm{R}^{2}$ of $54.7 \%$ as shown in Table 4.

\subsubsection{Effect Size $\left(\mathbf{f}^{\mathbf{2}}\right)$}

DMK had a large significant effect $(0.77)$ on DK and a small but significant effect $(0.12)$ on DP. Whereas, DK had a large significant effect (0.88) on DA and a medium significant effect on DP (0.16). Moreover, DA had a medium significant effect (0.17) on DP. Lastly, DP had a large significant effect (1.20) on HbA1c as shown in Table 4.

\subsubsection{Model Fit Index (SRMR)}

Model fit indices enable researchers to judge how well the hypothesized model fits the empirical data. As this research is exploratory and a formative model was tested, the recommended model fit measure is SRMR. Results presented in Table 4 showed that the obtained SRMR value (0.057) is less than 0.08 . Thus, the study concludes that the dietary consultation model which has been proposed in this research for more effective diabetes care has a considerable predictive power.

\subsubsection{Total Effects}

An interesting finding of this study was revealed by examining the total effects. Influence of DMK, DK, and DA on HbA1c was seen through mediating variable DP. DMK has the strongest significant total effect $(0.481)$ on HbA1c, followed by DK (0.434) and DA $(0.240) \mathrm{p}<0.001$ respectively. Therefore, healthcare givers should pay special emphasis on patients' DMK, DK and DA as these factors can also significantly influence HbA1c. Results are presented in Table 4.

\section{Table 4: Significance and relevance of formative inner model relationships}




\begin{tabular}{|c|c|c|c|c|c|c|c|c|}
\hline Path & VIF & $\mathbf{R}^{2}$ & p-value & $\mathbf{f}^{2}$ & p-value & Total Effects & Beta & p-value \\
\hline $\mathbf{D M K} \rightarrow \mathbf{D K}$ & 1.00 & 0.435 & $<0.001^{*}$ & 0.77 & $<0.001^{*}$ & \multirow{2}{*}{ DMK - HbA1c } & \multirow{2}{*}{0.481} & \multirow{2}{*}{$<0.001^{*}$} \\
\hline $\mathbf{D M K} \rightarrow \mathbf{D P}$ & 1.78 & 0.471 & $<0.001^{*}$ & 0.12 & $0.013^{\mathrm{f}}$ & & & \\
\hline $\mathbf{D K} \rightarrow \mathbf{D A}$ & 1.00 & & & 0.88 & $<0.001^{*}$ & \multirow{2}{*}{$\mathrm{DK} \rightarrow \mathrm{HbA1c}$} & \multirow{2}{*}{0.434} & \multirow{2}{*}{$<0.001^{*}$} \\
\hline $\mathrm{DK} \rightarrow \mathrm{DP}$ & 2.54 & 0.681 & $<0.001^{*}$ & 0.16 & $0.013^{\mathrm{f}}$ & & & \\
\hline $\mathbf{D A} \rightarrow \mathbf{D P}$ & 1.89 & & & 0.17 & $0.017^{\mathrm{I}}$ & \multirow{2}{*}{$\mathrm{DA} \rightarrow \mathrm{HbA1c}$} & \multirow{2}{*}{0.240} & \multirow{2}{*}{$<0.001^{*}$} \\
\hline $\mathrm{DP} \rightarrow \mathrm{HbA1c}$ & 1.00 & 0.547 & $<0.001^{*}$ & 1.20 & $<0.001^{*}$ & & & \\
\hline
\end{tabular}

Model Fit $($ SRMR $)=0.057(p<0.001)$

*significant at $1 \%$ level of significance

${ }^{\mathrm{I}}$ significant at $5 \%$ level of significance

\section{Discussions}

The findings of this study provide important implications for healthcare stakeholders that includes healthcare organizations, healthcare givers and, healthcare managers, etc. As reported in the literature, diabetes risk models do not fully capture the essence of diet and dietary behaviours which are considered as a foundation for self-management of diabetes. Moreover, it is evident that diet and related habits and practices have not been studied efficiently in developed and developing countries. Therefore, dietary consultation model proposed in this research can be considered as a significant contribution to diabetic society.

Our study is the first to empirically validate the influence of DMK on DK and DP using SEM approach. Results of our study helped in answering the gaps empirically that have been pointed out by previously published studies between DMK, DK and DP (Ntaate, 2015; Mufunda et al., 2012; Tesfaye et al., 1996). There is a scarcity of empirical evidence in the literature addressing the influence of DK on DA and DP among diabetics. Our study is the first to address this issue in detail. Odenigbo and Inya-Osuu (2012) from their study identified DK as an important factor that influenced DA. Our study findings also validated these findings by concluding that DK significantly influences DA. A study conducted by Ntaate (2015) on type 2 diabetics reported that DK was not significantly predicting DP, although, score of DK was good. Our study contradicts with this study as DK was significantly positively predicting DP. A recently conducted study found a moderate but significant association between knowledge and dietary behavior (Tavakoli et al., 2016). This result is almost similar to our study findings, where DK is significantly predicting DP. A study conducted by Primanda et al. (2011) also found a significant positive relationship between DK and dietary behaviors. Our study results are again consistent with this by findings a significant positive relationship between DK and DP.

Empirical evidence about the relationship between DA and DP among type 2 diabetics is limited. Ntaate (2015) conducted a study on type 2 diabetics reported that DA was not significantly predicting DP. Our study results contradict with this study as DA and DP are significantly positively related. Results of a study conducted on type 2 diabetics by Omondi et al. (2011) showed that attitude and norms followed by behavior control were 
the most significant predictors to follow the recommended diet. Our study results are consistent with this study, SEM analysis showed that DA was significantly related to DP.

Carbohydrates have the highest effect on blood glucose as compared to other macronutrients like lipids, fats, and protein (Sheard et al., 2004). This result is similar to our study findings, carbohydrates had the highest effect on HbA1c, followed by lipids and fats and proteins. A study conducted by Al-Kaabi et al. (2008) described a significant relationship between carbonated drinks and $\mathrm{HbA} 1 \mathrm{c}$. This finding is also congruent to our study, as drinks had a significant relationship with HbA1c. Franz et al. (2002) reported a significant decrease in $\mathrm{HbA1c}$ level with the increase of total vegetable and fruit intake. In our study, fruits and vegetables had a significant positive relationship with HbA1c; the reason is consuming fruits and vegetables having a high glycemic index (GI). Lee et al. (2012) studied the relationship between dairy products and HbA1c, results revealed a non-significant relationship. Our study results contradict with this finding by observing a significant positive relationship between dairy products and HbA1c. Midhet et al. (2010) conveyed that consumption of bakery items routinely can increase the risk of T2DM by 5.5 times. Results of our research also indicated sweets and bakery products have a significant positive effect on HbA1c. Harding et al. (2001) studied the relationship between fat consumption and HbA1c level. A significant positive relationship was reported between total fat intake and HbAlc. Our study results are similar to this by finding a significant positive relationship between lipids and fats and HbA1c.

\subsection{Contribution of study}

The study discusses its contribution in terms of theory and practice. Theoretically, the study extends management of DM by proposing a validated and integrated dietary consultation model for more effective diabetes care. Practically, the study proves that before guiding diabetics" about "what to eat and what to avoid," patients DMK, DK, and DA should be assessed first as these factors are interrelated and directly influence DP and HbA1c. Overall, the study makes a significant contribution to knowledge, better health outcomes for patients with diabetes, thus improving their quality of life.

\subsection{Limitations}

The research model used in this study may not be as comprehensive as it could have been. The identified influential factors were able to explain a portion of variances between them. There may be other factors that can influence studied parameters but were not included in the research model. For example, duration of diabetes, socioeconomic status, gender, occupation, marital status and education level can influence diabetes mellitus knowledge, dietary knowledge, dietary attitude and dietary practices. The HbA1c level can also be under and overestimated by some factors like having any blood disorder, HIV, kidney disease, etc. To rule out these, a more stringent inclusion criteria is required.

\section{Conclusions}

There is a great unawareness of healthy diet, poor eating habits, and void of exerciseculture in Arab society. It demands a three-dimensional programme of promoting early 
age exercise and nutrition education irrespective of region, gender and stratum of society without damaging their cultural norms and conventions. Overall, the findings of dietary consultation model facilitate a new healthcare paradigm which can give a better understanding of diabetes management at stakeholder level as well as at individual level. Healthcare givers can use this model alone or by integrating it with available diabetes risk models to carry out the dietary assessment of type 2 diabetics in a more effective way. Healthcare givers should pay special emphasis on diabetics diabetes mellitus knowledge, dietary knowledge and dietary attitude, as these factors influence each other onto dietary practices and HbA1c. Conducting the dietary assessment of diabetics at the initial stage and periodically can help in overall reduction in diabetes complications, thus improving the quality of life of patients.

\section{Acknowledgements}

We are thankful to Universiti Malaysia Pahang, Ministry of Higher Education, Malaysia for funding this research (Research Grant Vote No: RDU 130612).

\section{References}

1. Al-Khudairy, L., Stranges, S., Kumar, S., Al-Daghri, N., \& Rees, K. (2013). Dietary Factors and Type 2 Diabetes in the Middle East: What Is the Evidence for an Association?-A Systematic Review. Nutrients, 5(10), 3871-3897.

2. Al-Kaabi, J., Al-Maskari, F., Saadi, H., Afandi, B., Parkar, H., \& Nagelkerke, N. (2008). Assessment of dietary practice among diabetic patients in the United Arab Emirates. Rev Diabet Stud, 5(2), 110-115.

3. Akram, J., Aamir, A., Basit, A., Qureshi, M. S., Mehmood, T., Shahid, S. K., . . . Omair, A. (2011). Prevalence of peripheral arterial disease in type 2 diabetics in Pakistan. The Journal of the Pakistan Medical Association, 61(7), 644-648.

4. Amini, M. (2012). A cross-sectional study on food patterns and adiposity among individuals with abnormal glucose homeostasis. Archives of Iranian medicine, 15(3), 131.

5. Amorim, M. M. A., Ramos, N., Brito, M. J. M., \& Gazzinelli, M. F. (2014). Identity representations of people with diabetes. Qualitative health research, 24(7), 913-922.

6. Backman, D. R., Haddad, E. H., Lee, J. W., Johnston, P. K., \& Hodgkin, G. E. (2002). Psychosocial predictors of healthful dietary behavior in adolescents. Journal of nutrition education and behavior, 34(4), 184-193.

7. Brown, R., \& Ogden, J. (2004). Children's eating attitudes and behaviour: a study of the modelling and control theories of parental influence. Health education research, 19(3), 261-271.

8. Caballero, B. (2005). A nutrition paradox-underweight and obesity in developing countries. N Engl J Med, 352(15), 1514-1516.

9. Contento, I. R. (2007). Nutrition education: linking research, theory, and practice: Jones \& Bartlett Learning. 
10. Coon, K. A., Goldberg, J., Rogers, B. L., \& Tucker, K. L. (2001). Relationships between use of television during meals and children's food consumption patterns. Pediatrics, 107(1), e7-e7.

11. Cohen, J. (1992). A power primer. Psychological bulletin, 112(1), 155.

12. Chin WW. (1998). Commentary: Issues and opinion on structural equation modeling. Management Information System Quarterly, 22(1):7-16.

13. Chin, W. W. (1998). The partial least squares approach to structural equation modeling. Modern methods for business research, 295(2), 295-336.

14. Franz, M. J., Bantle, J. P., Beebe, C. A., Brunzell, J. D., Chiasson, J.-L., Garg, A., . . Mooradian, A. D. (2002). Evidence-based nutrition principles and recommendations for the treatment and prevention of diabetes and related complications. Diabetes Care, 25(1), 148-198.

15. Girois, S. B., Kumanyika, S. K., Morabia, A., \& Mauger, E. (2001). A comparison of knowledge and attitudes about diet and health among 35-to 75year-old adults in the United States and Geneva, Switzerland. American Journal of Public Health, 91(3), 418.

16. Hair, J. F., Ringle, C. M., \& Sarstedt, M. (2011). PLS-SEM: Indeed a silver bullet. Journal of Marketing theory and Practice, 19(2), 139-152.

17. Hair, Black, W. C., Babin, B. J., Anderson, R. E., \& Tatham, R. L. (2006). Multivariate Data Analysis (Vol. 6): Pearson Prentice Hall, NJ.

18. Hair, Hult, G. T. M., Ringle, C., \& Sarstedt, M. (2016). A primer on partial least squares structural equation modeling (PLS-SEM): Sage Publications.

19. Harding, A. H., Sargeant, L. A., Welch, A., Oakes, S., Luben, R. N., Bingham, S., ... Wareham, N. J. (2001). Fat consumption and HbA1c levels. Diabetes Care, 24(11), 1911-1916.

20. Henseler, J. (2017). Bridging Design and Behavioral Research With VarianceBased Structural Equation Modeling. Journal of Advertising, 1-15.

21. Hearnshaw, H., \& Lindenmeyer, A. (2006). What do we mean by adherence to treatment and advice for living with diabetes? A review of the literature on definitions and measurements. Diabetic medicine, 23(7), 720-728.

22. Hu, L. t., \& Bentler, P. M. (1999). Cutoff criteria for fit indexes in covariance structure analysis: Conventional criteria versus new alternatives. Structural equation modeling: a multidisciplinary journal, 6(1), 1-55.

23. Irfan, M. (2012). Diabetes among Saudis a major issue. Arab news, Jeddah. Assessed on (December 28, 2015). Retrieved from http://www.arabnews.com/diabetes-among-saudis-major-issue.

24. Jahner, S., Leimeister, J. M., Knebel, U., \& Krcmar, H. (2008). A cross-cultural comparison of perceived strategic importance of RFID for CIOs in Germany and Italy. Paper presented at the Hawaii International Conference on System Sciences, Proceedings of the 41st Annual. 
25. Kigaru, D. M. D., Loechl, C., Moleah, T., Macharia-Mutie, C., \& Ndungu, Z. W. (2015). Nutrition knowledge, attitude and practices among urban primary school children in Nairobi City, Kenya: a KAP study. BMC Nutrition, 1(1), 44.

26. Kulkarni, K., Castle, G., Gregory, R., Holmes, A., Leontos, C., Powers, M., ... . CARE, F. T. D. (1998). Nutrition practice guidelines for type 1 diabetes mellitus positively affect dietitian practices and patient outcomes. Journal of the American Dietetic Association, 98(1), 62-70.

27. Lanting, L. C., Joung, I. M., Vogel, I., Bootsma, A. H., Lamberts, S., \& Mackenbach, J. P. (2008). Ethnic differences in outcomes of diabetes care and the role of self-management behavior. Patient Education and Counseling, 72(1), 146154.

28. Lee, S. Y., \& Song, X. Y. (2012). Basic and advanced Bayesian structural equation modeling: With applications in the medical and behavioral sciences: John Wiley \& Sons.

29. Midhet, F. M., Al-Mohaimeed, A. A., \& Sharaf, F. K. (2010). Lifestyle related risk factors of type 2 diabetes mellitus in Saudi Arabia. Saudi Medical Journal, 31(7), 768-774.

30. Mirmiran, P., Azadbakht, L., \& Azizi, F. (2007). Dietary behaviour of Tehranian adolescents does not accord with their nutritional knowledge. Public health nutrition, 10(09), 897-901.

31. Monnier, L., Grimaldi, A., Charbonnel, B., Iannascoli, F., Lery, T., Garofano, A., $\&$ Childs, M. (2004). Management of French patients with type 2 diabetes mellitus in medical general practice: report of the Mediab observatory. Diabetes \& metabolism, 30(1), 35-42.

32. Mohamed, B. A., Almajwal, A. M., Saeed, A. A., \& Bani, I. A. (2013). Dietary practices among patients with type 2 diabetes in Riyadh, Saudi Arabia. J Food AGric Environ, 11(2), 110-114.

33. Mufunda, Esther, Wikby, Kerstin, Björn, A., \& Hjelm, K. (2012). Level and determinants of diabetes knowledge in patients with diabetes in Zimbabwe: a cross-sectional study. Pan African Medical Journal, 13(78).

34. Nasser, J. (2007). Evaluation of diabetes care in a primary care setting. Bahrain Med Bull, 29(2), 45-49.

35. Ng, S. W., Zaghloul, S., Ali, H., Harrison, G., \& Popkin, B. M. (2011). The prevalence and trends of overweight, obesity and nutrition-related noncommunicable diseases in the Arabian Gulf States. Obesity Reviews, 12(1), 1-13.

36. Ntaate, C. (2015). Dietary knowledge, attitude and practices of diabetic patients at Nsambya Hospital Kampala, Uganda. Stellenbosch: University of Stellenbosch.

37. Odenigbo, M., \& Inya-Osuu, J. (2012). Knowledge, Attitudes and Practices of People with Type 2 Diabetes Mellitus in a Tertiary Health Care Centre, Umuahia, Nigeria. Journal of Diabetes and Metabolism, 3 187-191. 
38. Omondi, D., Walingo, M. K., Mbagaya, G., \& Othuon, L. (2011). Predicting dietary practice behavior among type 2 diabetics using the theory of planned behavior and mixed methods design, 5(7):284-92.

39. Pastors, J. G., Warshaw, H., Daly, A., Franz, M., \& Kulkarni, K. (2002). The evidence for the effectiveness of medical nutrition therapy in diabetes management. Diabetes Care, 25(3), 608-613.

40. Pallant, J. (2011). SPSS Survival Manual; A step by step guide to data analysis using SPSS (4 edn), Everbest Printing Co: China.

41. Peat, J., \& Barton, B. (2008). Medical statistics: A guide to data analysis and critical appraisal: John Wiley \& Sons.

42. Pi-Sunyer, F. X., Maggio, C. A., McCarron, D. A., Reusser, M. E., Stern, J. S., Haynes, R. B., . . . Chait, A. (1999). Multicenter randomized trial of a comprehensive prepared meal program in type 2 diabetes. Diabetes Care, 22(2), 191-197.

43. Primanda, Y., Kritpracha, C., \& Thaniwattananon, P. (2011). Dietary Behaviors among Patients with Type 2 Diabetes Mellitus in Yogyakarta, Indonesia. Nurse Media Journal of Nursing, 1(2), 211-223.

44. Raj, C. P., \& Angadi, M. (2010). Hospital-based KAP study on diabetes in Bijapur, Karnataka. Indian J Med Spec, 1(2), 80-83.

45. Ramayah, T., Yeap, J. A., Ahmad, N. H., Halim, H. A., \& Rahman, S. A. (2017). Testing a Confirmatory model of Facebook Usage in SmartPLS using Consistent PLS. International Journal of Business and Innovation, 3(2), 1-14.

46. Saleh, F., Ara, F., \& Afnan, F. (2016). Assessment of Gap between Knowledge and Practices among Type 2 Diabetes Mellitus Patients at a Tertiary-Care Hospital in Bangladesh. Advances in Public Health (3).

47. Saleh, F., Mumu, S. J., Ara, F., Ali, L., Hossain, S., \& Ahmed, K. R. (2012). Knowledge, attitude and practice of type 2 diabetic patients regarding obesity: study in a tertiary care hospital in Bangladesh. Journal of Public Health in Africa, $3(1), 8$.

48. Sami, W., Ansari, T., Butt, N. S., Hamid, A., \& Rashid, M. (2016). Type 2 diabetes mellitus: Link between diet, HbA1c and complications. Australasian Medical Journal, 9(9).

49. Sami, W., Ansari, T., Butt, N. S., \& Ab Hamid, M. R. (2017, September). Psychometric evaluation of dietary habits questionnaire for type 2 diabetes mellitus. Journal of Physics: Conference Series 890(1), p. 012151.

50. Sami, W., Ansari, T., Butt, N. S., \& Ab Hamid, M. R. (2017). Effect of diet on type 2 diabetes mellitus: A review. International journal of health sciences, 11(2), 65.

51. Sheard, N. F., Clark, N. G., Brand-Miller, J. C., Franz, M. J., Pi-Sunyer, F. X., Mayer-Davis, E., . . . Geil, P. (2004). Dietary carbohydrate (amount and type) in the prevention and management of diabetes. Diabetes Care, 27(9), 2266-2271. 
52. Sindhu, L. (2014). How much do diabetic patients know about diabetes mellitus? Indian Journal of Forensic and Community Medicine, 1(1), 7-11.

53. Tabachnick, B., \& Fidell, L. (2007). Survival/failure analysis. Using multivariate statistics, 5, 506-566.

54. Tavakoli, H. R., Dini-Talatappeh, H., Rahmati-Najarkolaei, F., \& Fesharaki, M. G. (2016). Efficacy of HBM-Based Dietary Education Intervention on Knowledge, Attitude, and Behavior in Medical Students. Iranian Red Crescent Medical Journal, 18(11).

55. Tesfaye, S., Stevens, L., Stephenson, J., Fuller, J., Plater, M., \& IonescuTirgoviste, C. (1996). Prevalence of diabetic peripheral neuropathy and its relation to glycaemic control and potential risk factors: the Eurodiab IDDM Complications Study. Diabetologia, 39(11), 1377-1384.

56. Yaktine, A. L., \& Stallings, V. A. (2007). Nutrition standards for foods in schools: leading the way toward healthier youth: National Academies Press.

57. Waithaka, L. G. (2011). Nutritional knowledge, atitudes and practices in management of type 2 diabetes among adults in Nakuru provincial hospital.

58. Wild, S., Roglic, G., Green, A., Sicree, R., \& King, H. (2004). Global prevalence of diabetes estimates for the year 2000 and projections for 2030. Diabetes Care, 27(5), 1047-1053.

59. Worsley, A. (2002). Nutrition knowledge and food consumption: can nutrition knowledge change food behaviour? Asia Pacific journal of clinical nutrition, $11(\mathrm{~s} 3)$.

60. World Health Organization. (2005). Stepwise Approach to NCD Surveillance, Country-Specific Standard Report, Saudi Arabia. Saudi Arabia. Assessed on (January 30, 2016). Retrieved from http://www.who.int/chp/steps/2005_SaudiArabia_STEPS_Report_EN.pdf. 